\title{
Racial and seasonal differences in 25 -hydroxyvitamin $D$ detected in maternal sera frozen for over 40 years
}

\author{
Lisa M. Bodnar ${ }^{1,2,3,4 *}$, Janet M. Catov ${ }^{1,2,4}$, Katherine L. Wisner ${ }^{1,2,3,4}$ and Mark A. Klebanoff ${ }^{5}$ \\ ${ }^{1}$ Department of Epidemiology, University of Pittsburgh Graduate School of Public Health, A742 Crabtree Hall, \\ 130 DeSoto Street, Pittsburgh, PA 15261, USA \\ ${ }^{2}$ Department of Obstetrics, Gynecology, and Reproductive Sciences, University of Pittsburgh School of Medicine, \\ Pittsburgh, PA, USA \\ ${ }^{3}$ Department of Psychiatry, University of Pittsburgh School of Medicine, Pittsburgh, PA, USA \\ ${ }^{4}$ Magee-Women's Research Institute, Pittsburgh, PA, USA \\ ${ }^{5}$ Division of Epidemiology, Statistics and Prevention Research, National Institute of Child Health and Human Development, \\ National Institutes of Health, Bethesda, MD, USA
}

(Received 16 July 2007 - Revised 14 March 2008 - Accepted 17 March 2008 - First published online 23 April 2008)

Serum banks from large, decades-old epidemiological studies provide a valuable opportunity to explore the contributions of in utero vitamin D exposure to fetal origins of adult diseases. We compared 25-hydroxyvitamin D $(25(\mathrm{OH}) \mathrm{D})$ by race and season (two powerful predictors of vitamin D status) in sera frozen for $\geq 40$ years with sera frozen for $\leq 2$ years to determine whether $25(\mathrm{OH}) \mathrm{D}$ is stable enough to test vitamin D-related hypotheses. Data and sera came from seventy-nine pregnant women at 29-32 weeks' gestation in the Boston Collaborative Perinatal Project (CPP; 1959-66) and 124 women at 20-36 weeks' gestation in a 2003-2006 Pittsburgh cohort study. Multivariable linear regression models were used to test main and joint effects of race and season after confounder adjustment. In both cohorts, serum 25(OH)D levels were lower among black than white women (CPP 33.3 v. $46.7 \mathrm{nmol} / 1, P<0.01$; Pittsburgh 47.1 v. $89.6 \mathrm{nmol} / 1 ; P<0.0001$ ) and in winter than summer (CPP 32.7 v. $47.6 \mathrm{nmol} / 1, P<0.0001$; Pittsburgh 66.7 v. $89.8 \mathrm{nmol} / 1, P<0.001$ ), with no evidence of a race $\times$ season interaction in either cohort. Differences remained significant after confounder adjustment. When CPP and Pittsburgh results were compared, there was no significant difference in the race or season effects. The similarity in the relative change in $25(\mathrm{OH}) \mathrm{D}$ in these cohorts by two powerful predictors of vitamin D status suggests that, even if $25(\mathrm{OH})$ D deteriorated somewhat, it did so similarly across samples. Therefore, trends could be obtained from the decades-old serum data that would be relevant in exploring vitamin D-related hypotheses in future studies.

Vitamin D: Pregnancy: Racial groups: Seasons

Vitamin D deficiency is a global public health problem. Alarming rates of vitamin D deficiency are found throughout the world ${ }^{(1,2)}$. In one recent study of 7437 white British adults, the prevalence of serum 25-hydroxyvitamin D $(25(\mathrm{OH}) \mathrm{D})$ concentrations $<40$ and $<75 \mathrm{nmol} / \mathrm{l}$ was 47 and $87 \%$, respectively ${ }^{(3)}$. Ethnic minorities living in Britain and other northern countries are at even greater risk ${ }^{(4-7)}$. Vitamin $\mathrm{D}$ is unique in that it is either ingested orally or produced photochemically in the skin through exposure to UVB radiation. Pregnant women and their fetuses, the elderly, individuals with dark skin and individuals exposed to insufficient sunlight are particularly vulnerable to vitamin D deficiency ${ }^{(8-10)}$. In regions at high latitude, vitamin D status also worsens in winter, when less sunlight is available to synthesise cutaneous vitamin $\mathrm{D}^{(11-14)}$.

While awareness of this public health problem increases, a growing body of compelling research relates vitamin D insufficiency to a host of adverse outcomes. Low serum $25(\mathrm{OH}) \mathrm{D}$, the major circulating vitamin $\mathrm{D}$ metabolite and marker of vitamin D nutritional status ${ }^{(15,16)}$, has been associated with skeletal problems, diabetes, certain cancers, asthma, multiple sclerosis, rheumatoid arthritis, CVD and schizophrenia ${ }^{(2)}$. Moreover, maternal vitamin D deficiency may increase risk of adverse pregnancy outcomes ${ }^{(17)}$, and in utero vitamin D deficiency may be involved in fetal 'programming' of adult disorders ${ }^{(18)}$. Serum banks from large epidemiological studies conducted decades ago provide a valuable opportunity to confirm and expand our knowledge of the adverse health effects of low serum $25(\mathrm{OH}) \mathrm{D}$, including its role in fetal origins of adult disease. Serum $25(\mathrm{OH}) \mathrm{D}$ is extremely stable at $-20^{\circ} \mathrm{C}$ for 2 years $^{(19-21)}$ and is not sensitive to UV light exposure or repeated freezing and thawing ${ }^{(21,22)}$. Teams of investigators have used sera frozen for several decades to assess vitamin $\mathrm{D}$-outcome associations ${ }^{(23-26)}$. However, it is unknown

Abbreviations: ADUP, Antidepressant Use during Pregnancy; CPP, Collaborative Perinatal Project; IDS, Immunodiagnostic Systems Limited; 25(OH)D, 25-hydroxyvitamin D.

* Corresponding author: Dr Lisa M. Bodnar, fax +1 412624 7397, email bodnar@edc.pitt.edu 
whether prolonged storage causes analyte deterioration to an extent that prevents reliable testing of vitamin D-related hypotheses. Our objective was to determine whether $25(\mathrm{OH}) \mathrm{D}$ is stable enough after extremely long storage to test vitamin $\mathrm{D}$-disease associations by comparing differences in $25(\mathrm{OH}) \mathrm{D}$ by race and season (two powerful predictors of vitamin $\mathrm{D}$ status) in maternal sera frozen for over 40 years with maternal sera frozen for up to 2 years in two pregnancy cohort studies.

\section{Experimental methods}

Data and sera came from two pregnancy cohort studies. The Collaborative Perinatal Project (CPP; 1959-66) included 55908 pregnancies from women receiving care at twelve medical centres in the USA ${ }^{(27)}$. At enrolment, each prenatal visit, and during labour and delivery, detailed demographic, socio-economic and behavioural information and medical history were collected by in-person interview. Non-fasting maternal blood samples were drawn at repeated visits throughout gestation.

For our analysis, we selected women enrolled at the Boston CPP site $\left(42^{\circ} \mathrm{N}\right.$ latitude) who had non-fasting serum drawn at 29-32 weeks' gestation and delivered a singleton birth at 39-40 weeks' gestation. Based on an a priori power analysis to detect racial and seasonal differences in $25(\mathrm{OH}) \mathrm{D}$, we randomly selected twenty non-Hispanic white women with serum drawn in winter, twenty non-Hispanic white women with serum drawn in summer, twenty non-Hispanic black women with serum drawn in winter, and twenty non-Hispanic black women with serum drawn in summer. Winter was defined as January-February, and summer was defined as July-August. One vial of serum broke in transport, which left seventy-nine samples available for the final analysis. These seventy-nine samples were drawn from seventy-nine unique women.

The modern cohort was a group of pregnant women who participated in the Pittsburgh, Pennsylvania $\left(40^{\circ} \mathrm{N}\right.$ latitude) Antidepressant Use during Pregnancy (ADUP) study, an observational study of the effects of depression and antidepressant use on infant development. Women enrolled at $<20$ weeks' gestation after giving informed, written consent. At 20, 30 and 36 weeks' gestation, women provided a blood sample, and interviewer-administered questionnaires were used to collect detailed data on maternal factors. Beginning in May 2004, serum was banked for the analysis of nutritional biomarkers, including 25(OH)D. The study was approved by the University of Pittsburgh Institutional Review Board.

A total of 385 blood samples were analysed for serum $25(\mathrm{OH}) \mathrm{D}$. For this analysis, we selected all samples from women who self-identified their race as non-Hispanic white or non-Hispanic black and had a serum sample collected at 20-36 weeks' gestation in either January-February (winter), or July-August (summer). A total of 124 samples were available (ninety-eight white and twenty-six black) from 102 unique women. Although women had up to three pregnancy blood draws, only a fraction of women in this analysis had repeated samples because of the restrictions we put on the season of blood sampling. There was not an even distribution of women into the two racial groups because the study was small and only $20 \%$ were non-Hispanic black. Women using antidepressants were included in this analysis because we are unaware of any published evidence suggesting that such agents affect measurements of vitamin D metabolites.

\section{Quantification of serum 25-hydroxyvitamin D}

In the CPP, blood samples were allowed to clot for $30-60 \mathrm{~min}$, refrigerated for $8-24 \mathrm{~h}$ at $8^{\circ} \mathrm{C}$, and centrifuged. Serum was stored in clear vials at $-20^{\circ} \mathrm{C}$ and then shipped to the National Institutes of Health for permanent storage at $-20^{\circ} \mathrm{C}$. In September 2006, the selected samples were shipped to Pittsburgh on sufficient dry ice and stored at $-80^{\circ} \mathrm{C}$. In the over 40 years that CPP samples were available, the vast majority of the seventy-nine sera had never been thawed before assaying. In the ADUP study, blood samples were kept in the dark and allowed to clot. After centrifuging, serum was put into amber vials within $3 \mathrm{~h}$ of blood collection and stored at $-80^{\circ} \mathrm{C}$ until assay. A majority of the samples had never been thawed before assaying.

From June 2006 to September 2006, serum 25(OH)D in both cohorts was quantified in the same laboratory using a commercial ELISA from Immunodiagnostic Systems Limited (IDS; Tyne and Wear, UK) using $25 \mu \mathrm{l}$ serum as previously described $^{(8)}$. The inter-assay CV for the ELISA was $11.8 \%$. The ELISA could detect $25(\mathrm{OH}) \mathrm{D}$ in the range $5-300 \mathrm{nmol} / \mathrm{l}$. No sample in our analysis fell outside this detectable range. The ELISA recognised $100 \%$ of $25(\mathrm{OH}) \mathrm{D}_{3}$ and $75 \%$ of $25(\mathrm{OH}) \mathrm{D}_{2}$, but did not distinguish between these two forms. In our initial HPLC validation in a separate modern pregnancy cohort ${ }^{(8)}$ we observed that only three of thirty-two samples $(<10 \%)$ had any measurable $25(\mathrm{OH}) \mathrm{D}_{2}$, and within these samples, $25(\mathrm{OH}) \mathrm{D}_{2}$ accounted for only $10 \%$ of the total measurable $25(\mathrm{OH}) \mathrm{D}$.

We validated the ELISA results with those obtained using an HPLC method. The HPLC method for the quantification of $25(\mathrm{OH}) \mathrm{D}$ was modified from those published by Horst et al. ${ }^{(28)}$ and Alvarez \& De Mazancourt ${ }^{(29)}$. Briefly, thirtytwo serum samples collected from 1997-2001 and stored under similar conditions as above were spiked with an internal standard $\left(1-\alpha\right.$-hydroxyvitamin $\left.D_{3}\right)$ purchased from Sigma (St Louis, MO, USA) to a final concentration of $50 \mathrm{nmol} / \mathrm{l}$. Samples were processed two times by solid-phase extraction, first using $\mathrm{C}_{18}$ Sep-pak Cartridges and then using Silica Seppak Cartridges. After extraction, samples were evaporated to dryness under an $\mathrm{N}_{2}$ stream at $37^{\circ} \mathrm{C}$ and reconstituted in $100 \%$ acetonitrile. Fifty microlitres of the extracted samples were injected onto a prepared HPLC system that consisted of a Waters 600E pump, a Waters 717 plus autosampler and a Waters 996 photodiode array. Samples were separated on a C18 column $(150 \times 4.8 \mathrm{~mm}, 5 \mu \mathrm{m}$, Supelco $)$ with a $20 \times 4.8 \mathrm{~mm}$ guard column in line. The HPLC method could separate 1- $\alpha$-hydroxyvitamin $\mathrm{D}_{3}, 25(\mathrm{OH}) \mathrm{D}_{2}$ and $25(\mathrm{OH}) \mathrm{D}_{3}$ using isocratic conditions with a mobile phase that consisted of $87 \%$ acetonitrile with all components being detected at a wavelength of $265 \mathrm{~nm}$. The interassay CV for $25(\mathrm{OH}) \mathrm{D}_{3}$ using the HPLC method was $5.8 \%$. The sensitivity of the HPLC method was $<10 \mathrm{nmol} / 1$ and had a linear range to $1000 \mathrm{nmol} / \mathrm{l}$. The relationship between serum $25(\mathrm{OH}) \mathrm{D}$ concentrations obtained from the ELISA compared with HPLC was as follows: slope $=1 \cdot 14$, intercept $=22, r 0 \cdot 88$. 
In the 1960s when the CPP samples were collected, vitamin D-fortified foods in the USA were fortified with vitamin $\mathrm{D}_{2}$ rather than vitamin $\mathrm{D}_{3}$. Therefore, $25(\mathrm{OH}) \mathrm{D}_{2}$ may have been a larger proportion of total circulating $25(\mathrm{OH}) \mathrm{D}$ in the 1960 s than today. Because the IDS ELISA was able to quantify $75 \%$ of $25(\mathrm{OH}) \mathrm{D}_{2}$, a concern was that total circulating $25(\mathrm{OH}) \mathrm{D}$ concentrations in the CPP samples were underestimated using this method, and that this underestimation would obscure findings generated from our data. Thus, we performed a sensitivity analysis by additionally analysing CPP sera using a DiaSorin RIA (Stillwater, MN, USA), which detects $100 \%$ of $25(\mathrm{OH}) \mathrm{D}_{2}$ and $100 \%$ of $25(\mathrm{OH}) \mathrm{D}_{3}$. This assay required $50 \mu \mathrm{l}$ serum. The inter-assay $\mathrm{CV}$ was $9.0 \%$. The RIA could detect $25(\mathrm{OH}) \mathrm{D}$ in the range $3.75-250 \mathrm{nmol} / \mathrm{l}$. No sample in our analysis fell outside this detectable range.

Season of sample collection was defined as winter (January, February) or summer (July, August). Pre-pregnancy BMI (weight $(\mathrm{kg}) /$ height $(\mathrm{m})^{2}$ ) was based on measured height and maternal self-report of pre-pregnancy weight at the initial visit. Self-reported data were available from both cohorts on parity $(0, \geq 1)$, marital status (married, unmarried), smoking status (smoker, non-smoker) and maternal education ( $<12$ years, 12 years, $>12$ years). In the CPP, education, occupation and family income data were combined into a composite socio-economic status score (range 1 to 5$)^{(30)}$.

\section{Statistical analysis}

Serum $25(\mathrm{OH}) \mathrm{D}$ was not normally distributed, so we performed a log-transformation before performing statistical tests. We used an unpaired Student's $t$ test to compare unadjusted serum $25(\mathrm{OH}) \mathrm{D}$ by race and season within each cohort. Multivariable linear regression models were used to simultaneously test main and joint effects of race and season on log-serum $25(\mathrm{OH}) \mathrm{D}$ concentrations after adjusting for confounders. Separate models were built for the CPP and ADUP study. In the ADUP study model, generalised estimating equations were used to account for the non-independence of repeated serum measurements among women (Stata Statistical Software, release 8.0; Stata Corp. LP, College Station, TX, USA) ${ }^{(31)}$. We fitted parsimonious regression models by specifying full models with potential confounding variables (parity, age, marital status, pre-pregnancy BMI, gestational age, smoking, education (in the ADUP model only) and socio-economic status (in the CPP model only)). Potential confounders were considered to not be influential and were removed from the model if their inclusion did not satisfy our a priori changein-estimate criterion (a change in the coefficient of $>8 \%$ ). In the CPP model, marital status and socio-economic status met our definition of confounding, and in the ADUP model, marital status met our definition of confounding. Married women and women with high socio-economic status had higher 25(OH)D concentrations and were less likely to be non-Hispanic black. Race $\times$ season interactions were tested using Wald $P$ values $(\alpha=0 \cdot 10)$.

Lastly, we pooled data from both studies into one linear regression model employing generalised estimating equations for the repeated measures among ADUP participants that included indicator variables for race, season, cohort, sample gestational age categories, marital status, parity and maternal age categories. This model allowed us to test whether log-serum 25(OH)D concentrations were significantly different in the CPP compared with the ADUP study. Additionally, we included race $\times$ cohort and season $\times$ cohort interaction terms to test whether the race and/or season effects on 25(OH)D levels differed between the CPP and ADUP study $(\alpha=0 \cdot 10)$.

\section{Results}

Most women in the Boston CPP cohort were 20-29 years old, married, non-smokers, had one or more previous births, 12 years of education, and were in the middle socio-economic status group (Table 1). In the selected ADUP cohort, over three-quarters of women were white. The proportion of samples drawn in winter and summer was similar. A majority of ADUP women were 30 years or older, married, and nonsmokers, and had one or more previous birth and some college education.

When assayed with the IDS ELISA, the Boston CPP serum $25(\mathrm{OH}) \mathrm{D}$ concentrations were significantly lower among black than white women $(33.3$ (95\% CI 29.4, 37.9) v. 46.7 (95\% CI $41.0,53.1) \mathrm{nmol} / \mathrm{l} ; P<0.001)$ and in winter than in summer (32.7 (95\% CI 29.1, 36.7) v. 47.6 (95\% CI 41.7, 54.4) nmol/l; $P<0 \cdot 0001)$. As illustrated in Fig. 1 (a), the seasonal differences in $25(\mathrm{OH}) \mathrm{D}$ levels were similar among white

Table 1. Characteristics of women selected from the Boston Collaborative Perinatal Project (CPP) and the Pittsburgh Antidepressant Use during Pregnancy (ADUP) study

\begin{tabular}{|c|c|c|c|c|}
\hline & \multicolumn{2}{|c|}{ Boston CPP } & \multicolumn{2}{|c|}{$\begin{array}{l}\text { Pittsburgh } \\
\text { ADUP study* }\end{array}$} \\
\hline & $n$ & $\%$ & $n$ & $\%$ \\
\hline \multicolumn{5}{|l|}{ Maternal race } \\
\hline Non-Hispanic white & 39 & $49 \cdot 4$ & 98 & $79 \cdot 0$ \\
\hline Non-Hispanic black & 40 & $50 \cdot 6$ & 26 & $21 \cdot 0$ \\
\hline \multicolumn{5}{|c|}{ Season of sample collection } \\
\hline Winter & 40 & $50 \cdot 6$ & 57 & $46 \cdot 0$ \\
\hline Summer & 39 & $49 \cdot 4$ & 67 & $54 \cdot 0$ \\
\hline \multicolumn{5}{|l|}{ Maternal age } \\
\hline$<20$ years & 8 & $10 \cdot 1$ & 2 & 1.6 \\
\hline $20-29$ years & 52 & $65 \cdot 8$ & 48 & $38 \cdot 7$ \\
\hline$\geq 30$ years & 19 & $24 \cdot 1$ & 74 & $59 \cdot 7$ \\
\hline \multicolumn{5}{|l|}{ Marital status } \\
\hline Married & 73 & $92 \cdot 4$ & 83 & $66 \cdot 9$ \\
\hline Unmarried & 6 & $67 \cdot 6$ & 41 & $33 \cdot 1$ \\
\hline \multicolumn{5}{|l|}{ Smoking status } \\
\hline Smoker & 30 & $38 \cdot 0$ & 18 & $15 \cdot 1$ \\
\hline Non-smoker & 49 & $62 \cdot 0$ & 101 & 84.9 \\
\hline \multicolumn{5}{|l|}{ Parity } \\
\hline 0 & 23 & $29 \cdot 1$ & 48 & $38 \cdot 7$ \\
\hline 1 or more & 56 & $70 \cdot 9$ & 76 & $61 \cdot 3$ \\
\hline \multicolumn{5}{|l|}{ Maternal education } \\
\hline$<12$ years & 22 & $26 \cdot 6$ & 8 & $6 \cdot 6$ \\
\hline 12 years & 40 & $50 \cdot 6$ & 17 & $13 \cdot 9$ \\
\hline$>12$ years & 18 & $22 \cdot 8$ & 97 & $79 \cdot 5$ \\
\hline \multicolumn{5}{|c|}{ Socio-economic status score $†$} \\
\hline 1 (lowest) & 1 & $1 \cdot 3$ & \multicolumn{2}{|c|}{$\mathrm{N} / \mathrm{A}$} \\
\hline 2 & 6 & $7 \cdot 6$ & & \\
\hline 3 & 27 & $34 \cdot 2$ & & \\
\hline 4 & 23 & $29 \cdot 1$ & & \\
\hline 5 (highest) & 22 & $27 \cdot 9$ & & \\
\hline
\end{tabular}

N/A, not applicable.

* Some totals may not add to 124 because of missing data on some variables.

†For participants in the CPP, education, occupation and family income data were combined into a composite socio-economic status score ${ }^{(30)}$. 

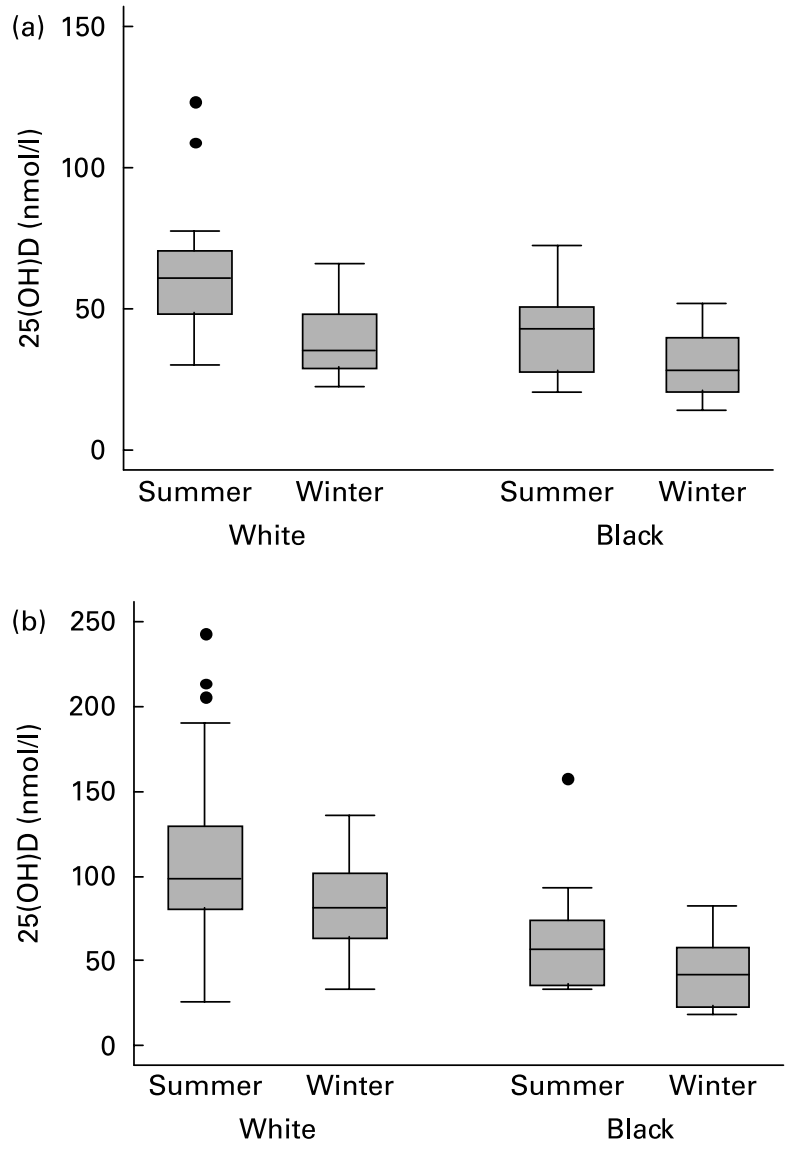

Fig. 1. Box plots of maternal serum 25-hydroxyvitamin D (25(OH)D) (nmol/l) by race and season among seventy-nine pregnant women in the Boston Collaborative Perinatal Project (CPP) (a) and 124 pregnant women in the Pittsburgh Antidepressant Use during Pregnancy (ADUP) study (b). Results are shown for Boston CPP sera assayed with an ELISA from Immunodiagnostic Systems Limited (Tyne and Wear, UK). Values are illustrated by box plots with the box representing the 25th and 75th percentiles (ends of boxes). The upper and lower whiskers are drawn from the box to the most extreme point within 1.5 interquartile range. The median is represented by the horizontal line in the box. Outliers are represented by dots. The mean concentration of serum log-25(OH)D in summer differed from that in winter for both white $(P<0.001)$ and black women $(P<0.05)$ in the CPP. In the Pittsburgh ADUP study, the mean concentration of log-serum 25(OH)D in summer differed from that in winter for white women $(P<0.01)$ and was borderline significant in black women $(P=0.05)$.

$(P<0.001)$ and black women $(P<0.05)$, with no race $\times$ season interaction detected $(P=0 \cdot 26)$. In the multivariable model, serum $25(\mathrm{OH}) \mathrm{D}$ levels were $24 \%$ lower in black women than white women $(P<0.01)$ and $32 \%$ lower in winter than summer $(P<0.001)$ (Table 2$)$, independent of marital status and socio-economic status. The race $\times$ season interaction remained non-significant. When the CPP samples were assayed with the DiaSorin RIA, 25(OH)D concentrations were, on average, $38 \%$ higher than when assayed with the IDS ELISA. However, the differences in mean $25(\mathrm{OH}) \mathrm{D}$ levels by race (white $63.3(95 \%$ CI $54.7,73.2) v$. black 46.8 $(95 \%$ CI 40.4, 54.1) nmol/l; $P<0.01$ ) and season (summer $65.5(95 \%$ CI $56.5,76.0) \quad v$. winter 45.2 (95\% CI 39.2, $51.7) \mathrm{nmol} / \mathrm{l} ; P<0.001)$ persisted. Moreover, multivariableadjusted $25(\mathrm{OH}) \mathrm{D}$ levels remained $20 \%$ lower in black women than white women $(P<0.05)$ and $32 \%$ lower in winter than summer $(P<0.001)$, with no evidence of a race $X$ season interaction.

Similar results were observed in the Pittsburgh ADUP study. Significantly lower concentrations of serum $25(\mathrm{OH}) \mathrm{D}$ were found among black compared with white women $(47 \cdot 1$ (95\% CI 38.0, 50.9) v. 89.6 (95\% CI 82.7, 97.2) nmol/1; $P<0.0001)$ and in winter than in summer $(66.7$ (95\% CI 58.6, 76.0) v. 89.8 (95\% CI 79.9, 100.9) nmol/1; $P<0.001)$. Fig. 1 (b) shows that these seasonal differences in $25(\mathrm{OH}) \mathrm{D}$ levels were evident among whites $(P<0.01)$ and were of borderline statistical significance in blacks $(P=0.05)$, probably due to the small size $(n 26)$. There was no race $\times$ season interaction in the ADUP data $(P=0 \cdot 39)$. In the multivariable model adjusting for marital status, concentrations of $25(\mathrm{OH}) \mathrm{D}$ were $41 \%$ lower in black women than white women $(P<0.001)$ and $24 \%$ lower in winter than summer $(P<0.001)$ (Table 2$)$. The race $\times$ season interaction remained non-significant after controlling for confounders. Exclusion of women with major depression had no impact on the results.

When the CPP and ADUP data were pooled into one multivariable model adjusting for sample gestational age, race, season, education, marital status, parity and maternal age, serum $25(\mathrm{OH}) \mathrm{D}$ concentrations were $42 \%$ lower in the CPP cohort than in the ADUP cohort $(P<0 \cdot 001)$. We did not observe either a race $\times$ cohort or a season $\times$ cohort interaction on log-serum $25(\mathrm{OH}) \mathrm{D}$ levels after covariate adjustment. When this analysis was repeated with CPP sera analysed with the DiaSorin RIA kit, 25(OH)D concentrations were $18 \%$ lower in the CPP than the ADUP cohorts after multivariable adjustment $(P<0 \cdot 05)$, with no race $X$ cohort or season $X$ cohort effects present.

\section{Discussion}

In the 40-year-old sera from pregnant women in the CPP, we detected expected racial and seasonal differences in $25(\mathrm{OH}) \mathrm{D}$, the indicator of vitamin D nutritional status. Serum 25(OH)D levels in the CPP samples were significantly lower in black women than white women, which is consistent with the knowledge that individuals with deeply pigmented skin produce vitamin D less efficiently than do individuals with less skin pigmentation ${ }^{(32)}$. Serum $25(\mathrm{OH}) \mathrm{D}$ levels were also significantly lower in winter, when UVB light is reduced, than in summer, when UVB light is plentiful ${ }^{(32)}$. Similar differences were observed in the ADUP cohort. These findings are consistent with previous literature on race and seasonal effects on $25(\mathrm{OH}) \mathrm{D}$ in childbearing-aged women (for example, Bodnar et al. ${ }^{(8)}$; Harris \& Dawson-Hughes ${ }^{(14)}$; Nesby-O'Dell et al. ${ }^{(33)}$ ).

Multivariable-adjusted serum 25(OH)D levels in the Boston CPP were $42 \%$ lower than the concentrations in the Pittsburgh ADUP samples when the IDS ELISA was used. Some of this difference was probably due to the assay's underestimation of $25(\mathrm{OH}) \mathrm{D}_{2}$, which probably made up a larger proportion of total circulating $25(\mathrm{OH}) \mathrm{D}$ in the CPP samples than modern samples because vitamin $\mathrm{D}_{2}$ was used to fortify foods in the 1960s. Indeed, when the CPP samples were analysed with the DiaSorin RIA, which captured $100 \%$ of both $25(\mathrm{OH}) \mathrm{D}_{2}$ and $25(\mathrm{OH}) \mathrm{D}_{3}$, we observed that concentrations were only $18 \%$ lower in CPP than the Pittsburgh ADUP samples. This lowering may, in fact, reflect analyte deterioration, 
Table 2. Relationship of race and season with maternal log-serum 25-hydroxyvitamin $D(25(\mathrm{OH}) \mathrm{D})$ concentration in the Boston Collaborative Perinatal Project (CPP) and the Pittsburgh Antidepressant Use during Pregnancy (ADUP) study

\begin{tabular}{|c|c|c|c|c|}
\hline & $\begin{array}{l}\text { Log-25(OH)D } \\
\text { adjusted } \beta\end{array}$ & SE & $\begin{array}{c}\text { Change in serum } \\
25(\mathrm{OH}) \mathrm{D}(\%)^{\star}\end{array}$ & $P$ \\
\hline \multicolumn{5}{|l|}{ Boston CPP $(n 79) \dagger$} \\
\hline \multicolumn{5}{|l|}{ Race } \\
\hline Black $v$. white & $-0.27 \ddagger$ & 0.08 & 24 & $<0.01$ \\
\hline \multicolumn{5}{|l|}{ Season } \\
\hline Winter $v$. summer & $-0.39 \ddagger$ & 0.08 & 32 & $<0.001$ \\
\hline \multicolumn{5}{|c|}{ Pittsburgh ADUP study ( $n$ 124) } \\
\hline \multicolumn{5}{|c|}{ Race } \\
\hline Black $v$. white & $-0.54 \S$ & $0 \cdot 11$ & 41 & $<0.001$ \\
\hline \multicolumn{5}{|l|}{ Season } \\
\hline Winter v. summer & $-0.28 \S$ & 0.08 & 24 & $<0.001$ \\
\hline
\end{tabular}

†Results shown here are with sera from the CPP assayed with an ELISA from Immunodiagnostic Systems Limited (Tyne and Wear, UK). Similar Results shown here are with sera from the CPP assayed with an ELISA from Immunodiagnostic Systems
results were observed with sera were analysed with a DiaSorin RIA (Stillwater, MN, USA; data not shown).

$\ddagger$ Adjusted for marital status and socio-economic status. Adjustment for other covariates had no meaningful impact on the results. The race $\times$ season interaction was not significant.

$\S$ Adjusted for marital status. Adjustment for other covariates had no meaningful impact on the results. The race $\times$ season interaction was not significant.

though we lacked the repeated measures of the same samples and standard over time to test this possibility. Nevertheless, it is important to note that even if there was deterioration in $25(\mathrm{OH}) \mathrm{D}$, it was not enough to reduce or eliminate our ability to detect relative racial and seasonal differences consistent with the literature. Indeed, we observed no race $\times$ cohort or season $\times$ cohort interactions when data from both the CPP and ADUP study were pooled. The lack of an interaction demonstrated that the magnitudes of the racial and seasonal differences in the 40-year-old CPP sera were similar to the racial and seasonal differences observed in sera from pregnant women in the ADUP study that were stored for up to 2 years. The similarity in the relative change in $25(\mathrm{OH}) \mathrm{D}$ in these two cohorts by two powerful predictors of vitamin $\mathrm{D}$ status suggests that, even if $25(\mathrm{OH}) \mathrm{D}$ deteriorated somewhat, it did so similarly across samples. Therefore, trends could be obtained from the decades-old serum data that would be relevant in exploring vitamin D-related hypotheses in future studies. Notably, if some degradation is present, traditional cut-points to define vitamin D sufficiency and insufficiency may not apply, and exploring vitamin $\mathrm{D}$ status as defined by the distributional cut-points (i.e. fourths based on quartiles) may be more appropriate.

The $25(\mathrm{OH}) \mathrm{D}$ levels in the CPP cohort were somewhat lower than the ADUP cohort; however, comparable with similar analytes measured in decades-old sera ${ }^{(34)}$, their distribution was well within the range published from other modern pregnancy cohorts ${ }^{(35-37)}$. Thus, the lower $25(\mathrm{OH}) \mathrm{D}$ concentrations in the CPP cohort may not be explained solely by analyte deterioration. Indeed, unmeasured lifestyle factors that varied between cohorts may also have contributed to differences we observed. On one hand, one might expect vitamin D status to be better in the 1960s than today, given the temporal increase in the public's awareness of the link between UVB exposure and skin damage; a reduction in the time spent outdoors, and the advent of topical sunscreens and sun-protective clothing. Yet, over the same period there has been a rise in both the use of dietary supplements ${ }^{(38)}$ and the availability and use in the USA of foods fortified with vitamin D (for example, some breakfast cereals, yogurts $)^{(39)}$. Dietary intake becomes an important source of vitamin D when sunlight exposure is limited ${ }^{(40)}$, so intake patterns may be especially relevant for populations residing in the northeastern USA, where there is limited ability to synthesise cutaneous vitamin D year round ${ }^{(11)}$. Certainly, the difference in the vitamin D status of these cohorts may be due to variation in sunlight exposure (as determined by time spent outdoors, environmental pollution and latitude ${ }^{(9)}$ ), use of prenatal vitamins; and/or intake of vitamin D through fortified foods. We did not have the appropriate covariate data or a large-enough sample size to rigorously explore these relationships in the present study.

Maternal third-trimester serum $25(\mathrm{OH}) \mathrm{D}$ has been previously measured among seventy-eight participants in the Boston and Providence CPP as part of a nested case-control study of maternal vitamin D and risk of schizophrenia in the offspring ${ }^{(25)}$. After measuring $25(\mathrm{OH}) \mathrm{D}$ with a DiaSorin RIA, the authors demonstrated similar differences in mean unadjusted $25(\mathrm{OH}) \mathrm{D}$ by race (black $27.4 \mathrm{nmol} / \mathrm{l}$; white $55.2 \mathrm{nmol} / \mathrm{l}$ ) and season (winter $30.5 \mathrm{nmol} / \mathrm{l}$; summer $64.0 \mathrm{nmol} / \mathrm{l}$ ), with absolute levels also lower than our modern cohort. Although these investigators used different analytical methods and did not design their study to compare relative differences in confounder-adjusted mean $25(\mathrm{OH}) \mathrm{D}$ by race and season with a modern cohort in a set of uncomplicated pregnancies, their findings support our conclusions that $25(\mathrm{OH}) \mathrm{D}$ is stable enough in 40-year-old sera to detect hypothesised differences by maternal exposures.

It would have been best to use fresh samples as the comparator in the present study. However, sera stored for up to 2 years, like the ADUP samples, have been shown to have no $25(\mathrm{OH}) \mathrm{D}$ deterioration ${ }^{(19-21)}$. We did not measure serum vitamin D-binding protein in the CPP and ADUP samples. Such analysis would have provided interesting information about the relative stability of bound $v$. free $25(\mathrm{OH}) \mathrm{D}$. Future studies will also be needed to precisely quantify the amount of deterioration in $25(\mathrm{OH}) \mathrm{D}$ over time so that appropriate absolute cut-points of vitamin $\mathrm{D}$ deficiency can be determined. 
Our data, which revealed that the relative differences in $25(\mathrm{OH}) \mathrm{D}$ by powerful predictors of vitamin $\mathrm{D}$ status remained in sera stored for over 40 years, suggest that $25(\mathrm{OH}) \mathrm{D}$ can be quantified in decades-old sera to reveal trends that can be used to explore vitamin D-related hypotheses, including studies of in utero vitamin $\mathrm{D}$ and risk of adult disease. Such studies may further clarify the role of vitamin D in the pathophysiology of disease states, broaden our understanding of the public health relevance of the epidemic of vitamin D deficiency, and cultivate ideas for preventing adverse health outcomes with nutritional interventions in susceptible populations.

\section{References}

1. Vieth R, Bischoff-Ferrari H, Boucher BJ, et al. (2007) The urgent need to recommend an intake of vitamin $\mathrm{D}$ that is effective. Am J Clin Nutr 85, 649-650.

2. Holick MF (2007) Vitamin D deficiency. $N$ Engl J Med 357 , 266-281.

3. Hypponen E \& Power C (2007) Hypovitaminosis D in British adults at age $45 \mathrm{y}$ : nationwide cohort study of dietary and lifestyle predictors. Am J Clin Nutr 85, 860-868.

4. Pal BR, Marshall T, James C \& Shaw NJ (2003) Distribution analysis of vitamin D highlights differences in population subgroups: preliminary observations from a pilot study in UK adults. J Endocrinol 179, 119-129.

5. Shaw NJ \& Pal BR (2002) Vitamin D eficiency in UK Asian families: activating a new concern. Arch Dis Child 86, $147-149$.

6. Looker AC, Dawson-Hughes B, Calvo MS, Gunter EW \& Sahyoun NR (2002) Serum 25-hydroxyvitamin D status of adolescents and adults in two seasonal subpopulations from NHANES III. Bone 30, 771-777.

7. Calvo MS \& Whiting SJ (2003) Prevalence of vitamin D insufficiency in Canada and the United States: importance to health status and efficacy of current food fortification and dietary supplement use. Nutr Rev 61, 107-113.

8. Bodnar LM, Simhan HN, Powers RW, Frank MP, Cooperstein E \& Roberts JM (2007) High prevalence of vitamin D insufficiency in black and white pregnant women residing in the northern United States and their neonates. J Nutr 137, 447-452.
9. Holick MF (1995) Environmental factors that influence the cutaneous production of vitamin D. Am J Clin Nutr 61, Suppl. 3, 638S-645S.

10. Salamone LM, Dallal GE, Zantos D, Makrauer F \& DawsonHughes B (1994) Contributions of vitamin D intake and seasonal sunlight exposure to plasma 25-hydroxyvitamin D concentration in elderly women. Am J Clin Nutr 59, 80-86.

11. Webb AR, Kline L \& Holick MF (1988) Influence of season and latitude on the cutaneous synthesis of vitamin D3: exposure to winter sunlight in Boston and Edmonton will not promote vitamin D3 synthesis in human skin. J Clin Endocrinol Metab 67, 373-378.

12. Brot C, Vestergaard P, Kolthoff N, Gram J, Hermann AP \& Sørensen OH (2001) Vitamin D status and its adequacy in healthy Danish perimenopausal women: relationships to dietary intake, sun exposure and serum parathyroid hormone. Br J Nutr 86, Suppl. 1, S97-S103.

13. McGrath JJ, Kimlin MG, Saha S, Eyles DW \& Parisi AV (2001) Vitamin D insufficiency in south-east Queensland. Med J Aust 174, 150-151.

14. Harris SS \& Dawson-Hughes B (1998) Seasonal changes in plasma 25-hydroxyvitamin D concentrations of young American black and white women. Am J Clin Nutr 67, 1232-1236.

15. Haddad JG \& Stamp TC (1974) Circulating 25-hydroxyvitamin D in man. Am J Med 57, 57-62.

16. Hollis BW (1996) Assessment of vitamin D nutritional and hormonal status: what to measure and how to do it. Calcif Tissue Int 58, 4-5.

17. Bodnar LM, Catov JM, Simhan HN, Holick MF, Powers RW \& Roberts JM (2007) Maternal vitamin D deficiency increases the risk of preeclampsia. J Clin Endocrinol Metab 92, 3517-3522.

18. McGrath J (2001) Does 'imprinting' with low prenatal vitamin D contribute to the risk of various adult disorders? Med Hypotheses 56, 367-371.

19. Ellis G \& Dixon K (1977) Sequential-saturation-type assay for serum 25-hydroxyvitamin D. Clin Chem 23, 855-862.

20. Stamp TC \& Round JM (1974) Seasonal changes in human plasma levels of 25-hydroxyvitamin D. Nature 247, 563-565.

21. Zerwekh JE (2004) The measurement of vitamin D: analytical aspects. Ann Clin Biochem 41, 272-281.

22. Lissner D, Mason RS \& Posen S (1981) Stability of vitamin D metabolites in human blood serum and plasma. Clin Chem 27, 773-774

23. Braun MM, Helzlsouer KJ, Hollis BW \& Comstock GW (1995) Prostate cancer and prediagnostic levels of serum vitamin D metabolites (Maryland, United States). Cancer Causes Control 6, 235-239.

24. Corder EH, Guess HA, Hulka BS, Friedman GD, Sadler M, Vollmer RT, Lobaugh B, Drezner MK, Vogelman JH \& Orentreich N (1993) Vitamin D and prostate cancer: a prediagnostic study with stored sera. Cancer Epidemiol Biomarkers Prev 2, 467-472.

25. McGrath J, Eyles D, Mowry B, Yolken R \& Buka S (2003) Low maternal vitamin $\mathrm{D}$ as a risk factor for schizophrenia: a pilot study using banked sera. Schizophr Res 63, 73-78.

26. Nomura AM, Stemmermann GN, Lee J, Kolonel LN, Chen TC, Turner A \& Holick MF (1998) Serum vitamin D metabolite levels and the subsequent development of prostate cancer (Hawaii, United States). Cancer Causes Control 9, 425-432.

27. Niswander K (1972) The Collaborative Perinatal Study of the National Institute of Neurological Diseases and Stroke: The Women and their Pregnancies. Philadelphia, PA: WB Saunders.

28. Horst RL, Reinhardt TA \& Hollis BW (1990) Improved methodology for the analysis of plasma vitamin D metabolites. Kidney Int Suppl 29, S28-S35.

29. Alvarez JC \& De Mazancourt P (2001) Rapid and sensitive highperformance liquid chromatographic method for simultaneous 
determination of retinol, $\alpha$-tocopherol, 25-hydroxyvitamin D3 and 25-hydroxyvitamin D2 in human plasma with photodiodearray ultraviolet detection. J Chromatogr B Biomed Sci Appl 755, 129-135.

30. Myrianthopoulos NC \& French KS (1968) An application of the U.S. Bureau of the Census socioeconomic index to a large, diversified patient population. Soc Sci Med 2, 283-299.

31. StataCorp (2003) Stata Statistical Software: Release 8.0. College Station, TX: Stata Corporation.

32. Holick MF (1987) Photosynthesis of vitamin D in the skin: effect of environmental and life-style variables. Fed Proc 46, $1876-1882$.

33. Nesby-O'Dell S, Scanlon KS, Cogswell ME, Gillespie C, Hollis BW, Looker AC, Allen C, Doughertly C, Gunter EW \& Bowman BA (2002) Hypovitaminosis D prevalence and determinants among African American and white women of reproductive age: third National Health and Nutrition Examination Survey, 1988-1994. Am J Clin Nutr 76, 187-192.

34. Stroud LR, Solomon C, Shenassa E, Papandonatos G, Niaura R, Lipsitt LP, Lewinn K \& Buka SL (2007) Long-term stability of maternal prenatal steroid hormones from the National
Collaborative Perinatal Project: still valid after all these years. Psychoneuroendocrinology 32, 140-150.

35. Hollis BW \& Pittard WB III (1984) Evaluation of the total fetomaternal vitamin $\mathrm{D}$ relationships at term: evidence for racial differences. J Clin Endocrinol Metab 59, 652-657.

36. Lee JM, Smith JR, Philipp BL, Chen TC, Mathieu J \& Holick MF (2007) Vitamin D deficiency in a healthy group of mothers and newborn infants. Clin Pediatr 46, 42-44.

37. van der Meer IM, Karamali NS, Boeke AJP, Lips P, Middelkoop BJC, Verhoeven I \& Wuister JD (2006) High prevalence of vitamin $\mathrm{D}$ deficiency in pregnant non-Western women in The Hague, Netherlands. Am J Clin Nutr 84, 350-353.

38. Millen AE, Dodd KW \& Subar AF (2004) Use of vitamin, mineral, nonvitamin, and nonmineral supplements in the United States: The 1987, 1992, and 2000 National Health Interview Survey results. J Am Diet Assoc 104, 942-950.

39. Calvo MS, Whiting SJ \& Barton CN (2004) Vitamin D fortification in the United States and Canada: current status and data needs. Am J Clin Nutr 80, Suppl. 6, 1710S-1716S.

40. Holick MF (2004) Vitamin D: importance in the prevention of cancers, type 1 diabetes, heart disease, and osteoporosis. Am J Clin Nutr 79, 362-371. 